\title{
Research on ERP General Part Development Strategy in Intelligent Manufacturing Era
}

\author{
Caixia $\mathrm{Li}$ and Jimei $\mathrm{Li}^{*}$ \\ Beijing Language and Culture University, Beijing, China \\ *Corresponding author
}

\begin{abstract}
China has gradually entered the era of intelligent manufacturing, the application demand of enterprise resource planning (ERP) is increasing. The development of ERP has some difficulties because of its business modules and complex functions. In order to reduce the development complexity of ERP, this paper studied the development strategy of the general part of ERP. The general part of ERP is similar to other system. The author used the code generation tool, developed the general part of the student project management subsystem and the student competition management subsystem. After testing, the two subsystems are in good use. So this paper summarized ERP general part development strategy that can achieve rapid development.
\end{abstract}

Keywords-intelligent manufacturing; ERP; rapid development; strategy research

\section{INTRODUCTION}

In recent years, the pattern of China's manufacturing industry transformation and development is good, which is closely related to the government's scientific and reasonable decision-making [1][2]. With the arrival of the fourth industrial revolution, intelligent manufacturing has gradually become the mainstream of manufacturing development. At present, China is actively developing towards intelligent manufacturing [3][4]. Intelligent manufacturing is one of the main paths for China to realize economic transformation and upgrading, and it has also become an objective trend for the development of the world's manufacturing industry [5]. Intelligent manufacturing is conducive to enterprises to simplify labor force and help China to get out of the long-term "low-end manufacturing" dilemma. China is gradually entering the era of intelligent manufacturing [6][7].

As an internal management information system, ERP not only helps enterprises to improve management efficiency, but also helps enterprises to ensure the safety of assets [8]. ERP has many advantages in enterprise internal control, such as realizing information sharing, improving information utilization rate, realizing fine management and so on [9]. With the development of information technology, the standardization degree of enterprises has been greatly improved, and domestic enterprises have begun to use ERP management software. With the increase of demand, the development of ERP is very rapid [10].

Under the background of intelligent manufacturing, ERP is more important for both enterprises and the whole manufacturing industry. However, there are still some problems in the application of ERP. For example, the management software of ERP management software for small enterprises is not perfect, so the service object is limited, it needs to expand the scope of service object [11], ERP has high development and maintenance costs [12]. In order to solve these problems, it is necessary to optimize the development strategy of ERP, so that ERP can not only turn in the direction of many enterprises, but also reduce its development cost, then the development of ERP is more adaptive to the development trend of intelligent manufacturing.

\section{PREVIOUS STUDIES}

With the above problems, first of all, let's look at the previous research about system development strategy. Before the 20th century, software development was limited by technology, capital and other things, and did not improve in an all-round way. After the 20th century, it realized a more comprehensive design of information system [13]. Zhanjun Hou and his team members (2009) put forward the structural method and prototype method of system development [14]. Wang Shuang (2016) pointed out that among the current development methods of management information system, structural method, object-oriented method and prototype method are recommended [15]. The above research shows that former method of system development focuses on the analysis and design in the early stage of system development. However, for the information system with many modules and complex functions such as ERP, it is not enough to rely on these methods alone. The programmers still need to work hard to write code, which is not conducive to the expansion of service scope and reduction of development cost of ERP, nor to the better adaptation of ERP development in intelligent manufacturing background. Bo Wang and his team members (2018) studied the automatic code generation technology, pointed out the principle and method of automatic code generation technology, but did not put it into practice [16].

\section{STRATEGy ANALYSIS}

The well-known enterprises developing ERP software in China such as yonyou, are relatively large enterprises. They use module development strategy to develop the system. However, the system development team members change faster, and developers may have different abilities and styles, which are not helpful to ensure the quality of ERP software and not enough for ERP to adapt to the environment of intelligent 
manufacturing. Hailang Chen (2018) once proposed code generation technology based on a template for management information system [17]. This technology realized the rapid development of the system by customizing the code template, and solves the problems of code's repetition and long development cycle in the development process of the information system. At the same time, the development method based on the template is also helpful to make up the gap between programmers, so that make the system quality more reliable. ERP belongs to management information system. Its development principle is similar to those ordinary management information system [18], but ERP is more complex than ordinary management information system, If the code generation technology can be applied to the development of ERP, ERP will surely develop better in the era of intelligent manufacturing.

\section{SYSTEM IMPLEMENTATION AND OPTIMIZATION}

In ERP, some module do not need to develop every time it is launched. ERP includes two parts, system management and enterprise application platform, system management includes account control, role and authority control and other general functions. The general part of ERP is system management. The functions of ERP general part are similar to those of other information systems. In this paper, the author used the code generation tool independently developed by Hua Zhi Cheng Si (Beijing) System Technology corporation, developed the general part of the system student project management subsystem and student competition management subsystem in order to study the development strategy of the general part of ERP. After testing, the two subsystems are in good use, and the system functions are safe and stable. As it is consistent with ERP, the ERP development strategy can be improved. Here is how to develop those two subsystems. The traditional system development steps are very complicated, but it only needs a few simple steps to develop a system with code generation tools. Imagine if this is applied to ERP, it will save a lot of manpower and time. The following describes the steps of developing the system with code generation tools:

\section{A. Database Design}

Here use SQL SERVER to design database. When designing a database, the relationship between tables and the fields presented on the interface should be considered, so as to better meet the needs of users in the later development process. This step is more important since that system's database involves hundreds or even thousands of forms, tens of thousands of fields;

\section{B. Code Generation}

Once the database is designed, connect the code generation tool with the database. In the code generation tool, you can see the designed data table, open a data table, and set the corresponding display forms for the fields, such as text box, pull-down menu, text field, etc. after the data table is edited, click the "generate" button to generate the code; The code uses the MVC framework, which consists of three parts: Model, Controller and Views[19]. Once the code is generated, add them to compiler;

\section{Interface Generation}

After the code is added to compiler, make it run in the compiler. Here uses visual studio as compiler. Figure I shows the generated interface (set one interface of the student project management subsystem as an example), It can be seen from Figure I that the interface designed by the code generator has uniform style, relatively complete functions, simple and beautiful appearance, and a uniform interface is very suitable for ERP.

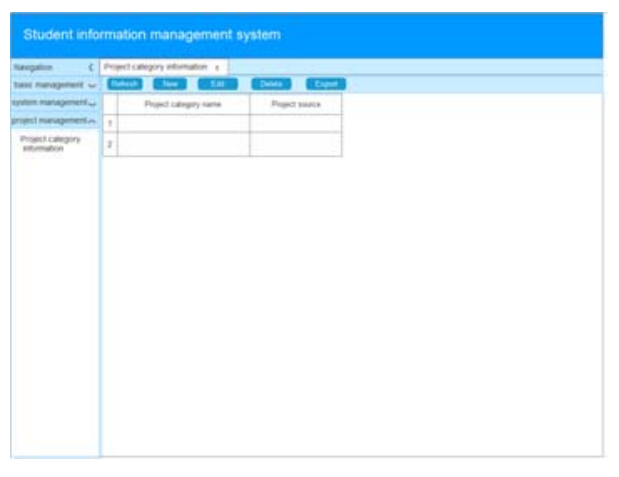

FIGURE I. GENERATED INTERFACE

The above steps are very simple, but it only generates the basic functions of the system, in practical application, Users have many needs, so there are more requirements for the system functions. The above steps could not satisfy all, so optimization is needed. Next take the role and permission functions as an example to introduce the optimization.

At present, there are only two aspects of permission control that can be performed by code generation tools without optimization:

\section{Interface Buttons Visibility}

Interface buttons mainly include "add", "Edit", "delete", "export" and "Refresh". This permission control means to control a user use one or several buttons' Function according his role. Figure II is the result of controlling, compared with Figure I and Figure II, it can be seen clearly that the authority control result of the interface button.

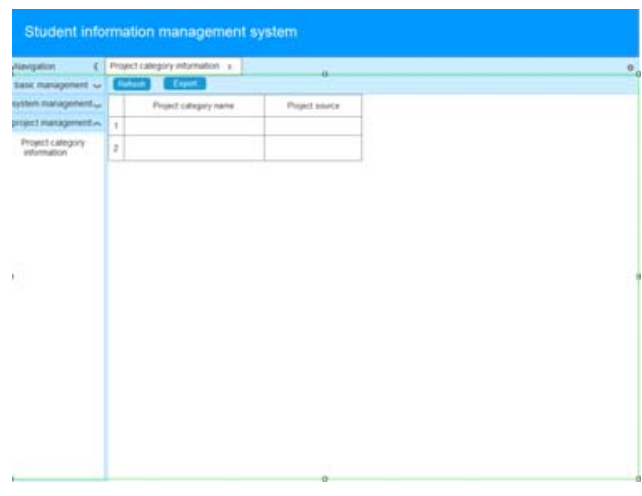

FIGURE II. AUTHORITY CONTROL RESULT

E. The Visibility of Records

If the current login role is a system administrator, 
administrator could see all interfaces, while others can only see the limited interfaces.

It can be seen from the above that, at present, the original authority control function of the code generation tool is relatively basic, but in practical application of the system, it often involves a variety of roles. Taking the role of student project management subsystem as examples, discuss the permissions how to optimize authority control function.

It can be seen from Table I that in addition to super administrator, the system also needs to control the authority of student project leader, student project team member and student project administrator, which is not available in the basic function of code generation tool. The author of this paper studies and solves this problem and realizes the authority control of different roles. Next introduce the method to solve this problem. The function of Controller in MVC frame is to connect the database and interface [20]. So optimize it in Controller, Figure III shows the Pseudo code of the optimization in Controller. First, the role ID of the current login user is extracted from the role table of the database, so as to figure out the role of the current login user. Then in the interface permission control part, according to different roles, SQL statements and database interfaces are used to control the interface and records that the current login user can see or cannot see, in this way, this system can achieve a more comprehensive permission control function.

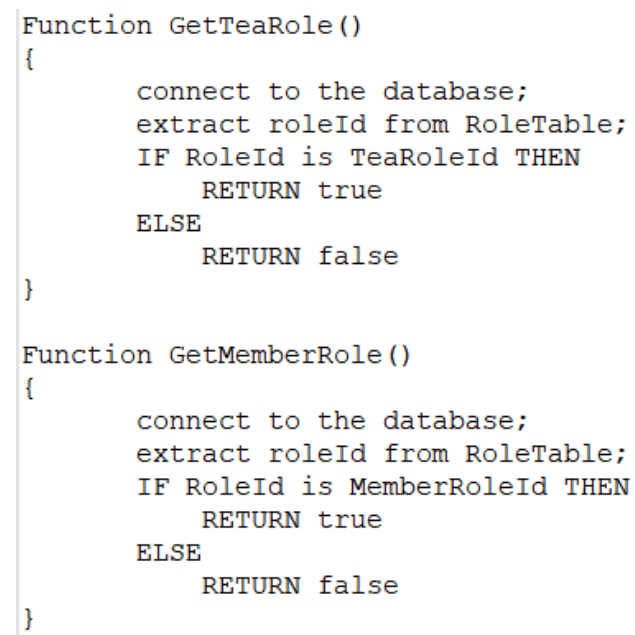

FIGURE III. AUTHORITY CONTROL RESULT

TABLE I. ROLE PERMISSIONS

\begin{tabular}{|c|c|c|}
\hline Role Name & Information Visibility & Operation authority \\
\hline $\begin{array}{c}\text { Leader of } \\
\text { Student } \\
\text { Project Team }\end{array}$ & $\begin{array}{c}\text { Only their own group's } \\
\text { information }\end{array}$ & $\begin{array}{c}\text { New, Delete, Edit, } \\
\text { Refresh, Export }\end{array}$ \\
\hline $\begin{array}{c}\text { Member of } \\
\text { Student } \\
\text { Project Team }\end{array}$ & $\begin{array}{c}\text { Only their own group's } \\
\text { information }\end{array}$ & Refresh, Export \\
\hline $\begin{array}{c}\text { Administrator } \\
\text { of Project }\end{array}$ & All group's information & Refresh, Export \\
\hline $\begin{array}{c}\text { Instructor of } \\
\text { Student } \\
\text { Project Team }\end{array}$ & $\begin{array}{c}\text { Only their own group's } \\
\text { information }\end{array}$ & Refresh, Export \\
\hline
\end{tabular}

In addition to the authority control function, the data association in database and data transmission between interfaces can also be optimized according to the needs. It could also be seen as a general part, which can be developed rapidly. In this article, the author will not introduce one by one. But from this, it could be known that the code generation tool is very flexible, and developers can add functions at any time as needed. ERP involves many modules and functions, so this develop strategy is very important to ERP development. Once ERP development used this strategy, it could be developed rapidly.

It can be seen from the above content that ERP general part still very complex. The code generation method is used to develop the system with a unified template, which is very convenient for ERP development. This paper mainly introduces a simple development strategy by taking the role and permission function as an example.

\section{CONCLUSION}

ERP is an integrated management information system which involves financial and business. In the era of intelligent manufacturing, ERP is very important for the development of enterprises. How to improve the development efficiency of ERP and reduce the maintenance cost is particularly urgent. This paper takes the development strategy of student project management subsystem and student competition subsystem as examples, introduces the convenience of code generation tools in development process. Because two subsystems' general parts are basically same as the general part of ERP, the author developed and tested these two subsystems and get positive results to prove that some functional modules of ERP can be developed rapidly through code generation tools. And this tool could also make sure that the system is safe, stable and flexible. This paper studies a convenient development strategy of the general part of the ERP. Hope it could be helpful to make ERP develop better in the era of intelligent manufacturing in the future.

\section{ACKNOWLEDGMENT}

This research project is supported by Science Foundation of Beijing Language and Culture University (supported by "the Fundamental Research Funds for the Central Universities”) (No: 18PT02, 17ZDJ02, GF201905, 20181003214), and by Computer Foundation Education Research Institute of National Colleges and Universities (No: 2019-AFCEC-100).

\section{REFERENCES}

[1] B. Zhang, The overall pattern of China's manufacturing industry transformation and upgrading [n]. Economic reference, 2019-05-29 (007). (references).

[2] T. Lei, Research on promoting high-quality development of new generation equipment manufacturing industry $[\mathrm{J}]$. Modern industrial economy and informatization, 2019,9 (07): 5-6.

[3] W. L. Chen, chief economist of China International Economic Exchange Center. The pattern of international manufacturing is undergoing profound adjustment [n]. Beijing Daily, August 12, 2019 (013)

[4] CCID, The development pattern of Intelligent Manufacturing in China in 2019 Potential outlook [n]. China Computer News, May 27, 2019 (012). 
[5] P. Zhao, Analysis of the development status and demand of China's intelligent manufacturing industry $[\mathrm{J}]$. Journal of Liaoning Transportation College, 2018,20 (05): 36-39.

[6] M. F. Yu, M. H. Wang, J. Y. Wang and J. Q. Sun, Research on enterprise intelligent manufacturing and Cost Stickiness [J]. Management accounting research, 2019,2 (04): 57-66 + 87-88.

[7] Y. Yin, G. Zhao. Business model of high-end equipment manufacturing enterprises based on Intelligent Manufacturing Innovation research: take Jinfeng technology as an example [J / OL]. Technological progress and Countermeasures: 1-10 [2019-11-07].

[8] H. X. Liu, Analysis of ERP system application in financial management of publishing house [J]. China management informatization, 2019,22 (14): 53-54

[9] X. F. Zeng, On the application core exploration of ERP system in enterprise internal control management [J]. Taxation, 2019,13 (18): 293

[10] W. Gao, Analysis of the application of ERP system in financial management [J]. Think tank era, 2019 (28): 40-41.

[11] H. P. Ding, UFIDA ERP management SWOT analysis of management software application and development [J]. China management informatization, 2018,21 (22): 84-85.

[12] Z. S. Wang, Design and implementation of a high configurable ERP system basic framework [J]. Information and computer (theoretical Edition), 2019 (11): 93-96.

[13] R. S. Lan, Comparative study on the development methods of management information system [J]. China Management information, 2016,19 (19): 172.

[14] Z. J. Hou, Z. C. Ge, On the development method of management information system [J]. Journal of Harbin Financial College, 2009 (01): 53-54.

[15] S. Wang, Research on development method of management information system [J]. Shandong industrial technology, 2016 (01): 276.

[16] B. Wang, X. F. Shu, X. Y. Wang, and R. Chen, Development status and trend of automatic code generation technology [J]. Journal of Xi'an University of Posts and telecommunications, 2018,23 (03): 1-12.

[17] H. L. Chen, Template based management information system code automatic generation [J]. Value engineering, 2018,37 (32): 213-216.

[18] Y. Li, H. Deng, Application of big data in enterprise management information system [J / OL]. Electronic technology and software engineering, 2019 (20): 172-173 [2019-11-07].

[19] T. L. Liu, Z. C. Zeng, Design and implementation of website under MVC Architecture [J / OL]. Computer technology and development, 2020 (02): 1-6 [2019-11-12].

[20] L. Sun, H. C. Yu, X. Y. Li, Research on MVC mode based on mobile Internet web development [J]. Science and technology wind, 2019 (23): 89-90 